\title{
7. DESCRIPTION AND PERFORMANCE OF THE SCRIPPS OCEAN BOTTOM SEISMOGRAPHS DURING THE NGENDEI EXPERIMENT ${ }^{1}$
}

\author{
John A. Orcutt, Scripps Institution of Oceanography, \\ Robert D. Moore, RD Moore Associates \\ and \\ Thomas H. Jordan, Massachusetts Institute of Technology²
}

\begin{abstract}
Six ocean bottom seismographs from the Scripps Institution of Oceanography were used in the Ngendei experiment in conjunction with the Marine Seismic System. The systems were modified to meet the requirements of this experiment. Significant buffer memory was added to several of the instruments to eliminate the effects of a rotating tape recorder housed in the same capsule as the inertial sensors. In addition, the response of the instruments was modified for the triggered portion of the experiment to improve the likelihood of detecting low frequency teleseismic signals. Finally, the software used by the seismograph's central processing unit was modified to allow simple, but important, changes in the operating characteristics immediately before launch. Each instrument was deployed several times and all capsules were recovered. Several deployments were found to be unsuccessful through acoustic diagnostics and several capsules returned to the surface shortly after launch because of small leakages revealed by the leak detectors. Nevertheless, all deployments following the correction of these faults were successful in returning data. This chapter outlines the operating characteristics of each instrument, describes the instrument response functions, lists the locations of the seismographs on the seafloor, and enumerates the events recorded by each of the capsules.
\end{abstract}

\section{INTRODUCTION}

The ocean bottom seismographs (OBS) used in the Ngendei Experiment were developed and constructed at the Scripps Institution of Oceanography. The design of these instruments was originally described by Moore et al. (1981), although a number of important changes were made to meet the operational requirements of the Ngendei expedition.

The sensors in the OBSs consist of a triaxial inertial sensor (Mark Products L-4-3D; Mark Products, Inc., 10507 Kinghorst Drive, Houston, TX 77072) and a deepwater hydrophone (Ocean and Atmospheric Science, Inc., Model E-2PD; Ocean and Atmospheric Science, Inc., 45 Palisade St., Dobbs Ferry, NY 10522). The natural period of the seismometers is $1 \mathrm{~Hz}$, the lowest free period currently in use in any operational bottom seismometer system.

The output of the seismometers, as well as the external hydrophone, is amplified by a broad-band, low-power complementary metal oxide semiconductor (CMOS) device with software selectable gains of $2^{N}$, where $N$ can range from 0 to 9 for a total gain range of 1 to 512 . The gains are controlled by the microcomputer, which seeks to maintain the long term average of the noise amplitude between a specified upper and lower level of the output of the analog-to-digital converter. This practice ensures that the instrument will record ground noise at

\footnotetext{
${ }^{1}$ Menard, H. W., Natland, J., Jordan, T. H., Orcutt, J. A., et al., Init. Repts. DSDP, 91: Washington (U.S. Govt. Printing Office).

2 Addresses: (Orcutt) Institute of Geophysics and Planetary Physics (A-025), Scripps Institution of Oceanography, La Jolla, CA 92093; (Moore) RD Moore Associates, 7868 Camino Raposa, San Diego, CA 92122; (Jordan) Department of Earth, Atmospheric and Planetary Sciences, Massachusetts Institute of Technology, Cambridge, MA 02139.
}

some level, but will make the bulk of the instrument's dynamic range available for recording large amplitude signals. The 12-bit analog-to-digital converter with the 9-bit gain ranging provides an overall dynamic range of $120 \mathrm{~dB}$.

The conservation of high dynamic range across a wide range of frequencies requires that the recorded noise be as flat as possible. Figure 1 illustrates the seafloor noise

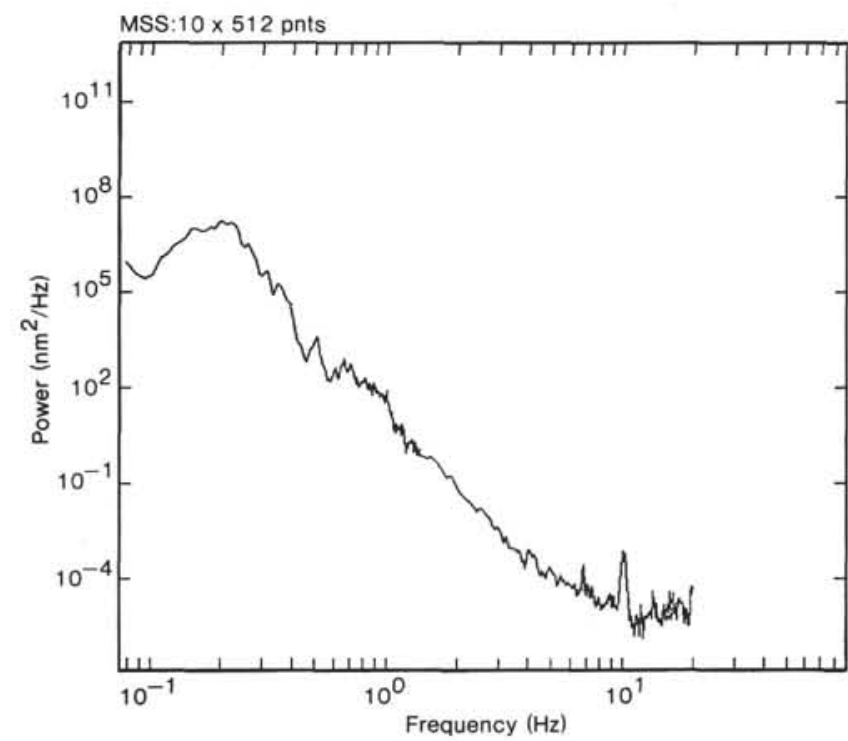

Figure 1. Displacement power spectrum for MSS for a period of time during Ngendei experiment (1210, 8 February 1983). Spectral estimate has been stabilized by stacking over ten realizations of the noise. The spike at $10 \mathrm{~Hz}$ results from Challenger thruster operation. 
as recorded by the Marine Seismic System (MSS) during the Ngendei experiment and is typical of seafloor noise in general. The power spectrum has been corrected for the response of the instrument and is demonstrably red, largely because of the substantial "microseismic" noise generated on the seafloor by weather patterns and resultant long-period gravity waves at the surface. The OBS is equipped with a notch filter within the microseism band below $1 \mathrm{~Hz}$ to depress the low frequency noise and boost the higher frequencies.

Before the Ngendei experiment, we added buffer memory to the system to postpone tape-recorder startup until after the arrivals of interest were recorded in the buffer. The tape recorders used in the system to record digital data in a serial format tend to shake the capsule during operation, thereby limiting the sensitivity of the instrument. Each of the buffer memories can store 65,536 words of data which, at the nominal 128 samples per second digitizing rate, is equivalent to $113 \mathrm{~s}$ of data on all four channels. As many as four of these boards can be used in any given instrument for a total of almost $8 \mathrm{~min}$. of solid-state recording. Because this facility was quite new and since our experience with refraction programs indicated the buffer memory was not absolutely essential, we elected to use the buffer capabilities only for the teleseismic portion of the experiment.

When on the seafloor, the OBSs can communicate with the parent ship through an acoustic link. This link, in its simplest mode, acts as a transponder and is used to pinpoint accurately the instrument on the seafloor. The acoustic link is also used as a telemetry link for sending capsule diagnostics to the ship regarding battery voltages, number of triggered events, the tilt status of the seismometers, the seafloor noise level, channel gain, etc. Finally, the telemetry link is used to command instrument release by firing one of the two available explosive bolts connecting the spherical package to the tripod anchor through a mechanical "OR" circuit. An independent pair of timed releases serve as a backup in the event that the acoustic command system fails.

\section{OPERATIONAL SUMMARY}

Each OBS was deployed several times to accomplish the goals of the experiment. The drops, launch goals, a summary of performance, and an identifier code are listed in Table 1.

The locations of the OBSs are listed in Table 2 and shown in Figures 2-5. These locations were determined using the OBS acoustics system and estimates of the ship's position obtained from satellite fixes as outlined by Creager and Dorman (1982). In most cases, the position of the ship at drop time is included to give an idea of the horizontal drift of the instruments during the transit to the seafloor. The position of LY2 on the seafloor is poorly known since time was not available for accurately locating the OBS using the acoustic system.

\section{SENSORS AND SIGNAL CONDITIONING}

The inertial sensors used in the Scripps OBS are standard seismometers with moving coil transducers. The output of these "velocity transducers" is further conditioned by active filters and preamplifiers to provide adequate levels for digitizing, to pre-whiten the earth noise present on the seafloor, and to provide adequate protection against aliasing.

The analog data streams for the seismometers and hydrophone are shown in Figure 6. The two systems are quite similar except for the lack of a "notch filter" for the hydrophone. The output of the seismometer is given by the standard form:

$$
e_{\mathrm{o}}=\frac{-2 \pi i G f\left(f / f_{\mathrm{o}}\right)^{2}}{1-\left(f / f_{\mathrm{o}}\right)^{2}+i f / f_{\mathrm{o}} Q} X
$$

where $e_{\mathrm{o}}=$ output voltage, $f_{\mathrm{o}}=$ seismometer natural frequency $(\mathrm{Hz})=1 \mathrm{~Hz}, G=$ seismometer generator constant $=417$ volts $/ \mathrm{m} / \mathrm{s}, Q=$ quality factor $=0.707$, $X=$ ground displacement (m), and $f_{\mathrm{o}}, G$, and $Q$ have been obtained from the equipment manufacturer, Mark Products, and were not explicitly measured at Scripps prior to the Ngendei experiment.

The preamplifier is essentially flat at all the frequencies of interest within the seismic passband and the gain is set by the OBS microcomputer in response to seismic noise levels on the seafloor. The gain is given by:

$$
e_{\mathrm{o}}=-\left(\frac{2^{n}}{1+\text { if } 2^{n} / f_{1}}\right) e_{\mathrm{i}} \quad(n=0,1, \ldots, 9)
$$

where $f_{1}$ is approximately $1.44 \times 10^{5} \mathrm{~Hz}$ and $e_{\mathrm{i}}$ is the input voltage. In the worst case, this gives a corner frequency of $282 \mathrm{~Hz}$ at a gain of 9 . This rolloff can, obviously, be neglected when computing the system response.

Anti-aliasing protection is provided by a total of five poles of low-pass filtering at a frequency of approximately $30 \mathrm{~Hz}$. One of these poles is included in the notch filter to be discussed next while the other four poles arise from the action of a pair of two-pole active filters. The response of the first of these is given by:

$$
e_{\mathrm{o}}=\frac{-54.4 i f}{1+19.4 i f-0.650 f^{2}-0.0218 i f^{3}} e_{\mathrm{i}}
$$

while that of the second can be calculated from:

$$
e_{\mathrm{o}}=\frac{-2.80}{1+i f / 30-(f / 30)^{2}} e_{\mathrm{i}}
$$

The Nyquist frequency of the Scripps OBSs is $64 \mathrm{~Hz}$. In the range from 0 to $30 \mathrm{~Hz}$, the worst case aliasing occurs at $30 \mathrm{~Hz}$ from frequencies at $64+(64-30)=98 \mathrm{~Hz}$. This level is reduced, through the anti-aliasing filters, by $51.4 \mathrm{~dB}$. The dynamic range of the analog-to-digital converter is $66 \mathrm{~dB}$ so the anti-aliasing protection should be adequate for most purposes.

The notch filter is introduced in the seismometer channel to prewhiten the input noise available to the analogto-digital converter and to prevent the markedly "red" seafloor noise spectrum from controlling the bulk of the 
Table 1. OBS operational summary.

\begin{tabular}{|c|c|c|c|c|c|c|c|c|c|}
\hline \multirow[b]{2}{*}{ OBS } & \multicolumn{3}{|r|}{ Deployment } & \multirow[b]{2}{*}{ Code } & \multicolumn{2}{|c|}{ Recovery } & \multirow{2}{*}{$\begin{array}{l}\text { No. of } \\
\text { events } \\
\text { recorded }\end{array}$} & \multirow[b]{2}{*}{ Comments } & \multirow{2}{*}{$\begin{array}{l}\text { Clock drift } \\
\text { (ms/day) } \\
\text { (all slow) }\end{array}$} \\
\hline & Time & Date & Purpose & & Time & Date & & & \\
\hline PHRED & 0640 & $23 \mathrm{Jan}$ & Teleseismic and noise level recording & PH1 & 0850 & $7 \mathrm{Feb}$ & 358 & & 73.609 \\
\hline JANICE & 0626 & 24 Jan & Teleseismic and noise level recording & JA1 & 0715 & 31 Jan & 91 & $\begin{array}{l}\text { Fired } 2 \text { nd bolt on leak indication upon } \\
\text { recovery. Apparently leaked a drop of } \\
\text { seawater by O-ring at low pressure. }\end{array}$ & 44.189 \\
\hline KAREN & 0102 & $29 \mathrm{Jan}$ & Seismic refraction and noise level recording & KA1 & 0807 & $9 \mathrm{Feb}$ & 758 & & 105.791 \\
\hline JUAN & 1104 & 29 Jan & Seismic refraction and noise level recording & JU1 & 0535 & $9 \mathrm{Feb}$ & 789 & $\begin{array}{l}\text { Horizontal channels did not record properly } \\
\text { probably due to excessive tilt. }\end{array}$ & 43.712 \\
\hline SUZY & 0039 & $30 \mathrm{Jan}$ & Seismic refraction and noise level recording & SU1 & 0556 & $10 \mathrm{Feb}$ & 894 & & 133.991 \\
\hline LYNN & 1124 & 30 Jan & Seismic refraction and noise level recording & LY1 & 0817 & $10 \mathrm{Feb}$ & 898 & $\begin{array}{l}\text { Horizontal channel } 2 \text { did not record properly } \\
\text { probably due to excessive tilt. }\end{array}$ & 34.112 \\
\hline JANICE & 0455 & $1 \mathrm{Feb}$ & Teleseismic and noise level recording & $\mathrm{JA} 2$ & 0815 & 3 Feb & 0 & $\begin{array}{l}\text { A/D board had been placed in wrong slot in } \\
\text { card cage upon checkout. This is only } \\
\text { card requiring a specific location. }\end{array}$ & - \\
\hline JANICE & 1433 & 5 Feb & Teleseismic and noise level recording & JA3 & 1520 & $22 \mathrm{Mar}$ & 114 & & 36.669 \\
\hline PHRED & 0152 & 9 Feb & Teleseismic and noise level recording & PH2 & 0905 & $23 \mathrm{Mar}$ & 158 & & 75.217 \\
\hline JUAN & 1136 & $10 \mathrm{Feb}$ & Teleseismic and noise level recording & JU2 & 0250 & $11 \mathrm{Feb}$ & 4 & $\begin{array}{l}\text { Recalled after teleseismic launch when } \\
\text { acoustics indicated one horizontal gain } \\
\text { was extremely high ( } 9 \text { ). Seismometer } \\
\text { might have been tilted. }\end{array}$ & 21.878 \\
\hline SUZY & 2247 & $10 \mathrm{Feb}$ & Teleseismic and noise level recording & SU2 & 0531 & $22 \mathrm{Mar}$ & 153 & & 133.719 \\
\hline JUAN & 1124 & $11 \mathrm{Feb}$ & Teleseismic and noise level recording & JU3 & 1100 & $22 \mathrm{Mar}$ & 119 & & 39.420 \\
\hline KAREN & 2142 & $11 \mathrm{Feb}$ & Teleseismic and noise level recording & KA2 & 0600 & $23 \mathrm{Mar}$ & 112 & & 103.999 \\
\hline LYNN & 1357 & $12 \mathrm{Feb}$ & Teleseismic and noise level recording & LY2 & 1040 & $23 \mathrm{Mar}$ & 282 & & 31.655 \\
\hline
\end{tabular}

Table 2. OBS seafloor positions.

\begin{tabular}{|c|c|c|c|c|c|c|c|c|c|}
\hline \multirow[b]{2}{*}{ Deployment } & \multirow{2}{*}{$\begin{array}{l}\text { Latitude } \\
\left({ }^{\circ} \mathrm{S}\right)\end{array}$} & \multirow{2}{*}{$\begin{array}{l}\text { Longitude } \\
\left({ }^{\circ} \mathrm{W}\right)\end{array}$} & \multirow{2}{*}{$\begin{array}{l}\text { Water } \\
\text { depth } \\
\text { (m) }\end{array}$} & \multicolumn{3}{|c|}{$\begin{array}{c}\text { Absolute error ellipse } \\
1 \mathrm{SD}(\mathrm{km})\end{array}$} & \multicolumn{3}{|c|}{$\begin{array}{c}\text { Relative error ellipse } \\
1 \mathrm{SD}(\mathrm{km})\end{array}$} \\
\hline & & & & $\mathrm{S}$ major & $\mathrm{S}$ minor & Azimuth & S major & $\mathrm{S}$ minor & Azimuth \\
\hline KA1 ref & 23.81733 & 165.52758 & 5612 & 0.155 & 0.079 & 148 & 0.027 & 0.014 & 139 \\
\hline JU1 ref & 23.82024 & 165.53244 & 5618 & 0.133 & 0.080 & 143 & 0.037 & 0.014 & 135 \\
\hline SU1 ref & 23.81737 & 165.52745 & 5612 & 0.119 & 0.081 & 151 & 0.027 & 0.019 & 122 \\
\hline LY1 ref & 23.82077 & 165.53115 & 5603 & 0.126 & 0.082 & 145 & 0.027 & 0.019 & 122 \\
\hline PH1 tele1 & 23.94182 & 165.76130 & 5676 & 0.115 & 0.073 & 162 & 0.160 & 0.071 & 138 \\
\hline JAl telel & 23.93398 & 165.78653 & 5704 & 0.458 & 0.191 & 137 & 0.315 & 0.138 & 138 \\
\hline JA2 tele1 & 23.93612 & 165.76672 & 5717 & 0.124 & 0.085 & 170 & 0.161 & 0.078 & 139 \\
\hline $\mathrm{JA} 3$ tele 2 & 23.81823 & 165.52578 & 5605 & 0.080 & 0.062 & 158 & 0.071 & 0.047 & 139 \\
\hline PH2 tele2 & 23.82394 & 165.53820 & 5544 & 0.149 & 0.075 & 136 & 0.106 & 0.024 & 125 \\
\hline KA2 tele2 & 23.80939 & 165.54157 & 5593 & 0.145 & 0.103 & 115 & 0.116 & 0.056 & 119 \\
\hline LY2 tele2 & 23.81230 & 165.55120 & 5503 & \multicolumn{6}{|c|}{ (position based on drop point) } \\
\hline SU2 tele2 & 23.85997 & 165.29674 & 5654 & 0.292 & 0.190 & 10 & & NA & \\
\hline JU3 tele2 & 24.04531 & 165.53030 & 5579 & 0.151 & 0.118 & 69 & & NA & \\
\hline
\end{tabular}

dynamic range of the 12-bit converter. The response of the notch filter is given by:

$$
\begin{aligned}
e_{\mathrm{o}}= & -1.97 \frac{1+i f / 0.504}{1+i f / 0.10} \cdot \frac{1+i f / 1.52}{1+i f / 5.03} \cdot \frac{1}{1+i f / 32.2} \\
& \cdot \frac{(1+i f / 1.52)^{2}}{(1+i f / 5.03)(1+i f / 5.12)} e_{\mathrm{i}}
\end{aligned}
$$

The modulus of this filter is plotted in Figure 7. The bottom of the notch occurs at a frequency of about $0.6 \mathrm{~Hz}$ and the maximum high-frequency boost is achieved at a frequency of $15 \mathrm{~Hz}$. The action of the single pole of anti-aliasing filtering can be seen at higher frequencies. This filter is very well suited to recording explosion sources in a refraction experiment when the primary frequencies of interest lie at $5 \mathrm{~Hz}$ and higher. In this case, the low frequencies in the vicinity of the microseism peak are of little interest and the notch filter actively suppresses these contributions.

The filter is, however, poorly suited to triggering on and recording distant earthquakes. Experience with the use of the Scripps OBSs in the past for earthquake recording had indicated that triggering on microearthquakes was quite straightforward and no events were missed when compared to recordings obtained from a continuously recording analog instrument (Riedesel et al., 1982). On the other hand, the instruments rarely triggered on teleseisms. Following discussions with Dr. William Prothero, who had designed an effective trigger for teleseisms (Prothero, 1979), we elected to remove the notch filter for the teleseismic recording portion of Ngendei. This removes the high-frequency boost and emphasizes the low-frequency portion of the spectrum. Figure 8 illustrates the overall response of the Scripps OBS before and after the removal of the notch filter. The teleseismic recording portion of the experiment was very successful, as discussed later in this volume.

The output of the hydrophone is given by:

$$
e_{\mathrm{o}}=25.1 \times 10^{-7} \frac{0.0314 i f}{1+0.0314 i f} P
$$




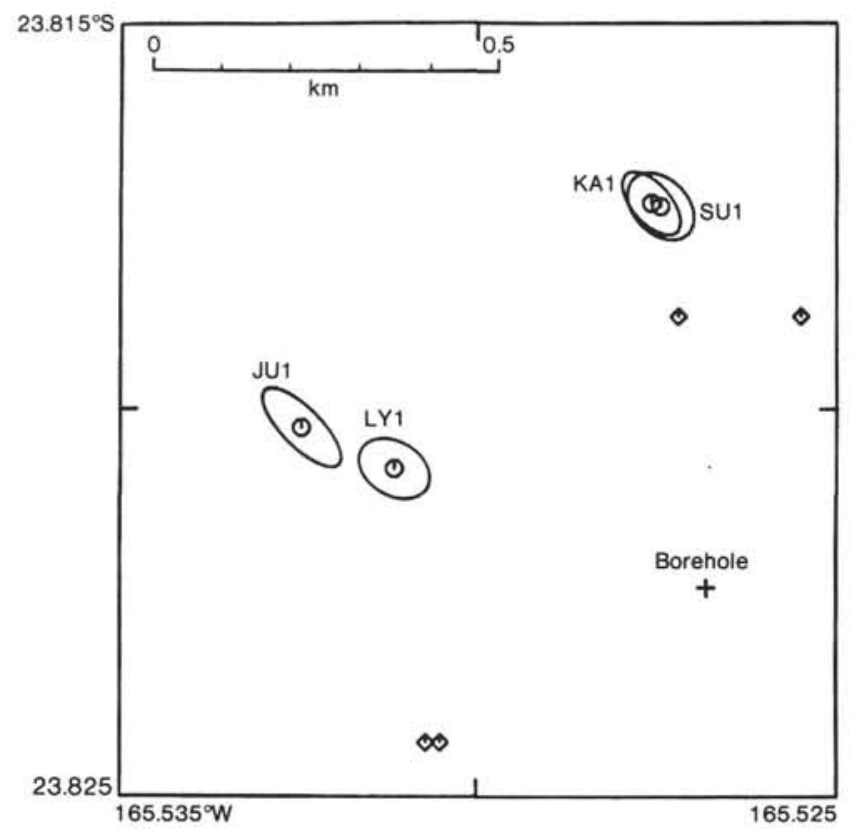

Figure 2. OBS locations for the refraction experiment relative to a common center of mass. Error ellipses are $95 \%$ confidence limits. Diamonds show the approximate location of the OBS drop points. The OBS locations are keyed with the notations (e.g., KA1) from Tables 1 and 2 .

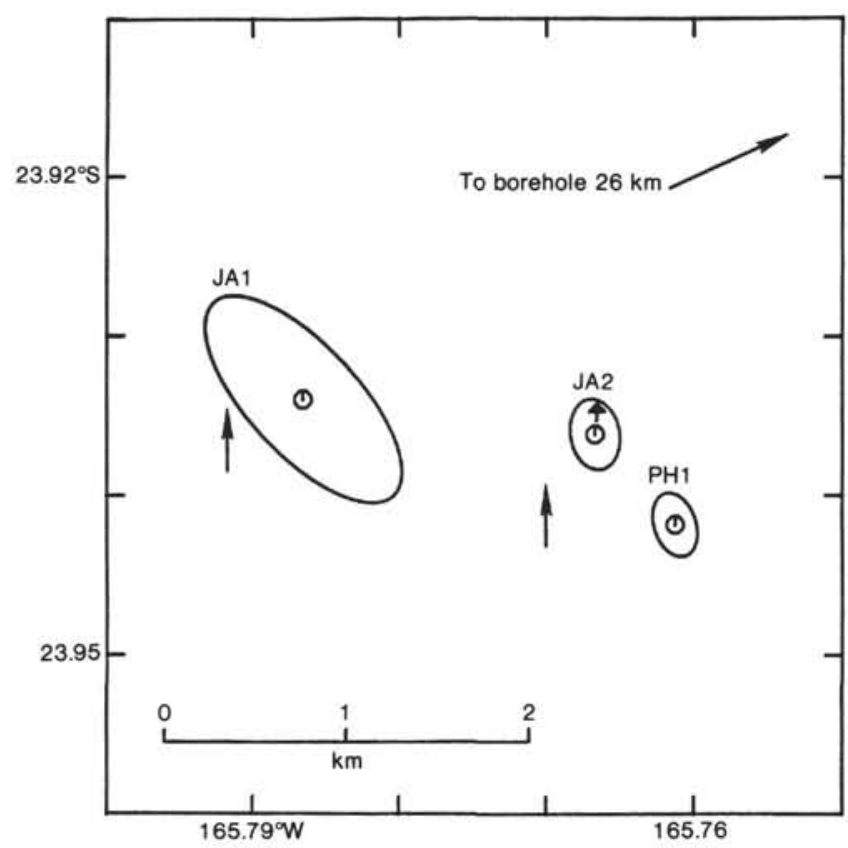

Figure 3. Absolute OBS locations for the initial teleseismic experiment. Error ellipses are $95 \%$ confidence limits; drop points are shown as up arrows.

where $P$ is the pressure in Pascals. The hydrophone preamp response can be calculated from:

$$
e_{\mathrm{o}}=\frac{87.4 i f}{1+43.7 i f-1.51 f^{2}-0.052 i f^{3}} e_{\mathrm{i}}
$$

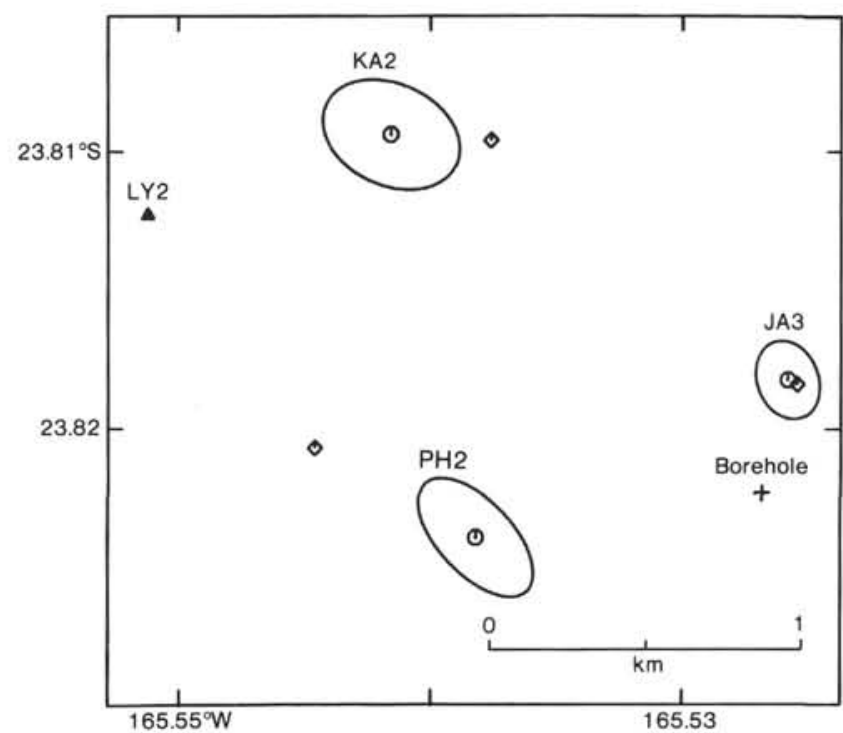

Figure 4. Absolute OBS locations near the borehole for the 45-day teleseismic experiment. Error ellipses are $95 \%$ confidence limits: drop points are shown as diamonds. The location for LY2 is approximate because no joint ranging information is available for this deployment.

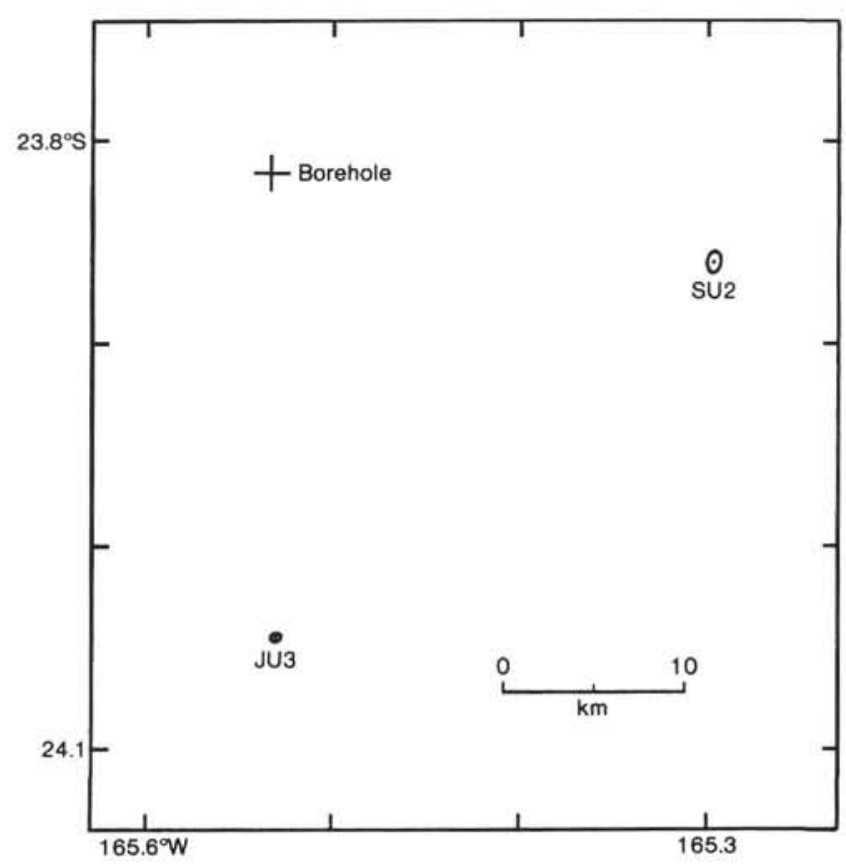

Figure 5. Absolute OBS locations away from the borehole for the 45 day teleseismic experiment. Error ellipses are $95 \%$ confidence limits.

This hydrophone preamplifier is followed by the same preamplifier as discussed above for the seismometers and by two active anti-aliasing filters. The response of the hydrophone channel is illustrated in Figure 9.

\section{OBS ACOUSTICS}

The acoustics system on the Scripps OBSs was designed and constructed at Scripps after a long history 
Typical seismometer channel

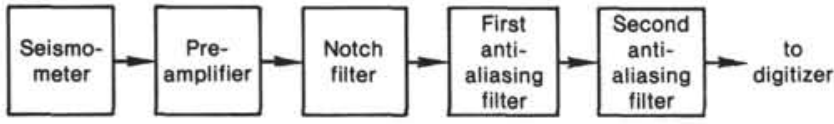

Hydrophone channel

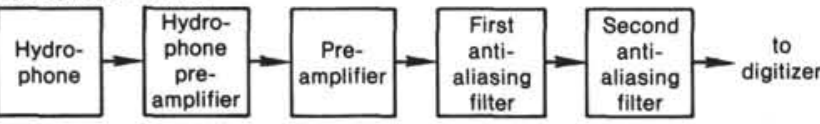

Figure 6. Data streams for OBS inertial and hydrophone channels.

Notch filter for prewhitening is used only on the inertial channels.

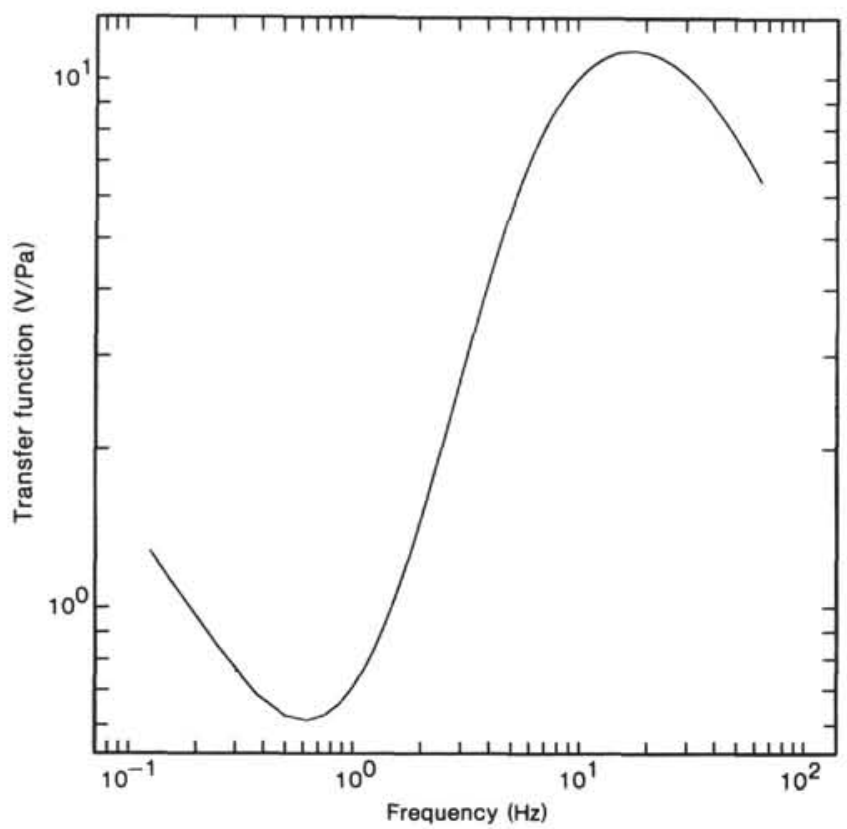

Figure 7. Amplitude response of notch filter used to prewhiten seismic noise. The filter minimum is near the microseism peak, whereas the maximum is near frequencies of interest in explosion seismology.

of difficulties with a popular commercial system. It is intended to perform a number of functions, the most rudimentary of which involves service as an acoustic transponder. This is extremely useful in locating the individual instruments on the seafloor and can be accomplished to an accuracy on the order of $10 \mathrm{~m}$ using a least squares algorithm (Creager and Dorman, 1982). The use of OBSs on the seafloor in array studies requires extremely accurate locations for the sensors, which cannot be provided by ship's navigation at launch time or by the relatively inaccurate timing provided by low-frequency explosions. We found, during the Ngendei experiment, that an OBS could drift by more than a kilometer from the time of release until it settled on the seafloor. Recordings of explosions can be used to locate the seismographs on the bottom, but the accuracy is limited both by the frequencies detected by the seismic recording system on board the seafloor instrument and the not negligible timing inaccuracies associated with the shot times and the clock times in the recorder. The acoustic system allows the ship

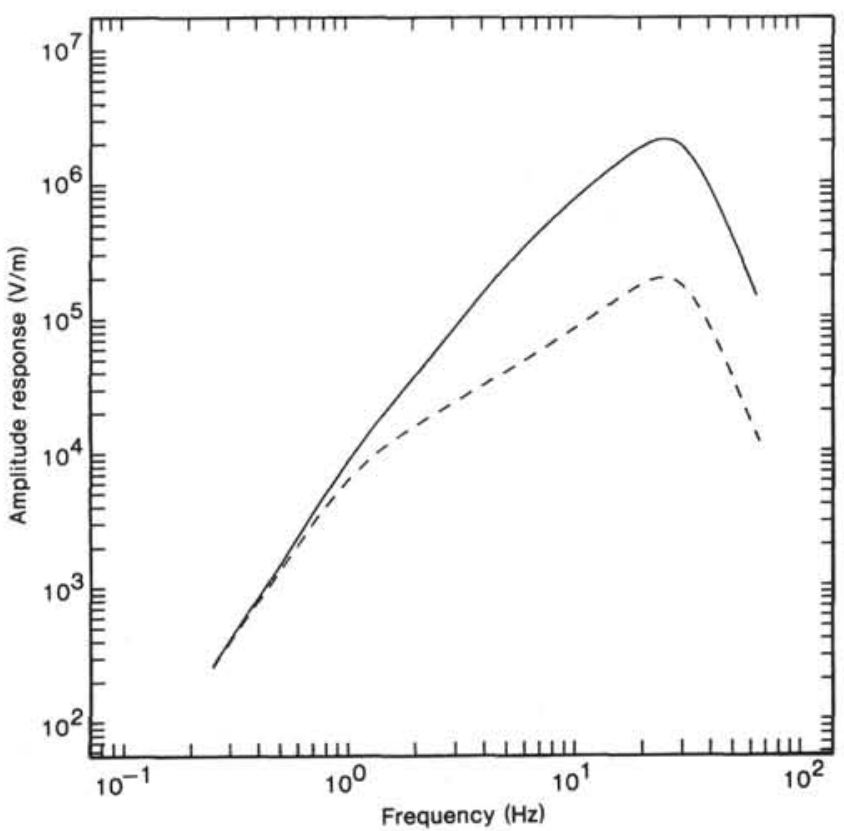

Figure 8. Amplitude of OBS response function with (solid curve) and without (dashed curve) notch filter. The removal of the notch filter emphasizes the low frequencies needed for triggering on teleseismic arrivals.

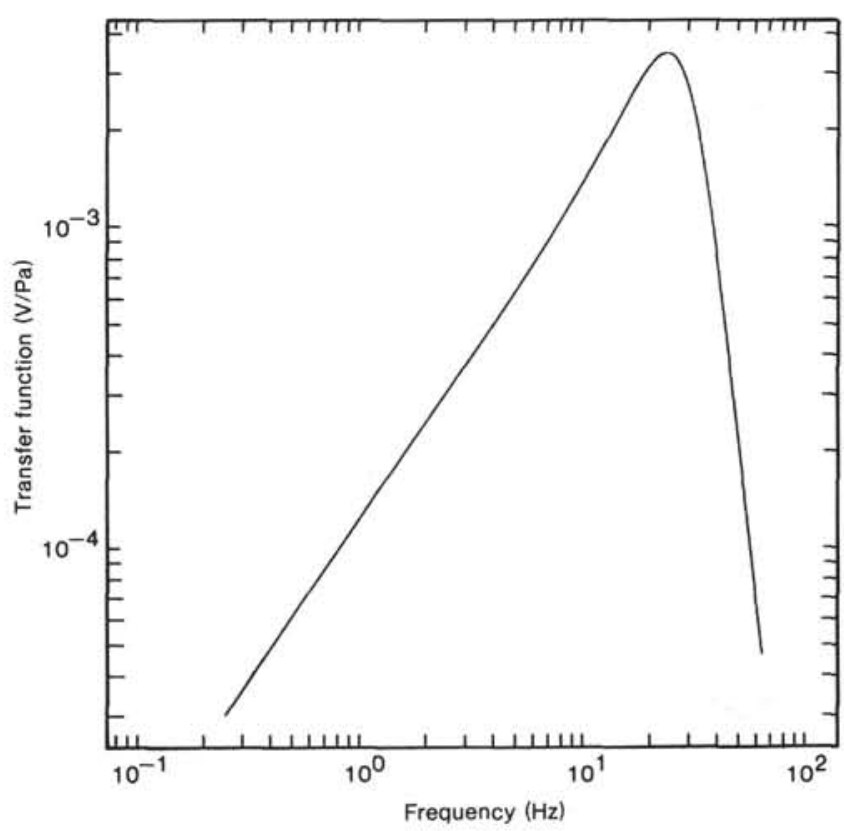

Figure 9. Response of OBS hydrophone channel. A notch filter is not used to prewhiten the hydrophone response.

to send transpond commands throughout the time that a transit satellite is above the horizon and to interpolate the replies to the actual time of the fix.

The acoustics system also permits low-speed telemetry from the instrument, which can be useful for checking the "health" of the electronics and assessing the need for early recovery and relaunch. Finally, because the sys- 
tem is able to recognize specific commands, the acoustics are used to fire the explosive bolts that release the OBS from the bottom. This acoustic release system is considered the primary means for recalling the OBSs, whereas timed release is regarded as a backup system. The instrument is also released automatically if a leak into the capsule is detected. The flexibility afforded by the release-upon-command feature is very helpful in executing an experiment; many hours of ship time can be lost while waiting on a timed release.

The OBSs are interrogated on the seafloor at a frequency of $12.5 \mathrm{kHz}$ and reply at frequencies between 8.0 and $15.5 \mathrm{kHz}$. Given the discrete reply frequencies, individual instruments can be readily identified by the ship's electronics. The collection of a number of ranges during several satellite fixes with the ship at different positions with respect to the seafloor array allows the accurate determination of the instrument locations. The locations of individual instruments during the Ngendei experiment are given in the subsequent chapters that discuss specific portions of the program.

Following a diagnostics command on the seafloor, the OBSs reply to the command with strings of 12 bits which comprise four octal words. A one is denoted by two "pings" while a zero is a single ping. The diagnostics that are sent by the OBS depend upon the time elapsed since the capsule was launched. The first diagnostics command is sent to the OBS after it has undergone final preparations, but is still sitting in the checkout van. The reply to this first command is two strings of octal 2's, 22222222 , or 010010010010010010010010. Subsequent diagnostics commands result in replies of 0007000700070007 until the seismometer is first leveled on the bottom. The time interval between the first set of diagnostics and the leveling is set by the computer software, but is generally $3 \mathrm{hr}$. This period is measured by the OBS computer in seconds so that $3 \mathrm{hr}$. easily overflows the IM6100's 12-bit word. This is true of many of the variables that the computer must use so that a "double-precision" 24-bit word becomes necessary. The two 12-bit words that hold the bits for this time delay are called WAITLL and WAITMM.

Following the initial wait, which is designed to ensure the instrument has reached the seafloor in the study area, the seismometer is leveled and the instrument enters a setup period. This setup period is also controlled by the computer, and the time interval is entered in the two variables RUNTML and RUNTMM to comprise another double precision variable. This time is generally set to $4096 \mathrm{~s}$ to correspond to four time constants of the algorithm that is used to calculate the long-term average (LTA) of the seafloor noise. The LTA is used to individually set channel gains and to remove any analog amplifier offset voltage. This variable is discussed in greater detail below. During the setup period, the acoustic diagnostics reply with 3333333333333333 if the system is tilted by less than $15^{\circ}$ and leveling has been successful or by 7171717171717171 if the capsule is tilted by more than $15^{\circ}$ and leveling is impossible. The investigator must at this time make a decision about whether to recall the seismograph or to accept the probable loss of the horizontal data and possible degradation of the ver- tical data. None of the OBSs launched during the Ngendei experiment had to be recalled to correct excessive tilt problems.

The computer activates the "normal" diagnostics sequence once the setup is complete. These diagnostics consist of 11 groups of four-digit octal words which report on the health of the system in detail (Fig. 10). The 7007 words at the beginning and end of the sequence are used to allow the listener to arrange the intervening words in correct order and to identify the beginning and end of the diagnostics. This is critically important in situations that constantly arise when the signal-to-noise ratio is marginal and the individual bits are difficult to detect. The bits are sent at exact intervals of $4 \mathrm{~s}$. The bits B3-B11 in the status word are decoded as:

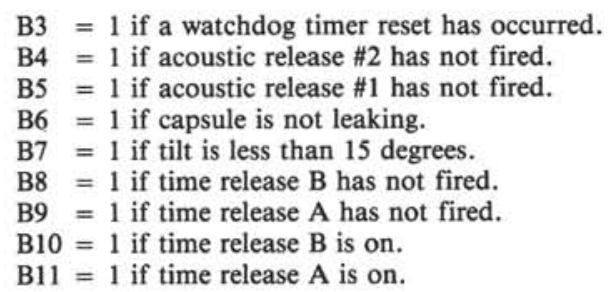

The normal state while on the bottom is 000011111 111. The watchdog timer is a hardware device used to reset the program in the computer if, for some reason, the program has crashed. This timer checks to ensure that several specific instructions have been performed within a specific time period and resets and reinitializes the program if a problem is noted. The operation of the real-time clock is not affected by the computer reset. Normally, the computer should indicate no watchdog timer resets and none were noted during the Ngendei experiment on any of the capsules.

The instrument can be released from the bottom with an acoustic release command. The computer returns the words 63146314 upon the receipt of a release command, and subsequent diagnostics commands from the ship return the same pair of words. Finally, the instrument will release its anchor upon detecting a leak in the capsule. When the leak is detected, the instrument sends the words 04210421 every $128 \mathrm{~s}$ for eight times. Subsequent diagnostics result in the words 04210421 to notify the ship that a recovery is imminent.

The Scripps OBSs at one time used an acoustics command system which depended upon the temporal relationship of an "arm" and a frequency-encoded "command" pulse. Any signals arriving in the brief period (1 s) between the arm and command signals would "disarm" the acoustics unit. Such a system works quite nicely when the acoustic transceiver is several meters off the seafloor or if the seafloor is well sedimented. However, in a rough seafloor environment, reverberations from the bottom and surrounding topography frequently disarm the acoustics system. This "temporal" approach was replaced during the past 2 yr. with a "frequency-domain" system which is sensitive to eight frequencies:
A: $12.650 \mathrm{KHz}$
C: $13.050 \mathrm{KHz}$
B: $12.850 \mathrm{KHz}$
E: $13.650 \mathrm{KHz}$
D: $13.250 \mathrm{KHz}$
G: $14.050 \mathrm{KHz} \quad \mathrm{H}: 14.250 \mathrm{KHz}$ 


\begin{tabular}{|c|c|c|c|c|c|c|c|c|c|c|c|c|}
\hline 7007 & 1 & 1 & 1 & 0 & 0 & 0 & 0 & 0 & 0 & 1 & 1 & 1 \\
\hline Status word & 0 & 0 & 0 & B3 & B4 & B5 & B6 & B7 & B8 & B9 & B10 & B11 \\
\hline Trigger count & - & - & - & - & - & - & - & - & - & - & - & - \\
\hline Trigger ratio & - & - & - & - & - & - & - & - & - & - & - & - \\
\hline Gains & 0 & 0 & & [Ch & el 이 & & 0 & 0 & & [Ch & el 1] & \\
\hline Gains & 0 & 0 & & [Ch & el 2] & & 0 & 0 & & [Ch & el 3] & \\
\hline+6 V supply & - & - & - & - & - & - & - & - & - & - & - & - \\
\hline + 5 V supply & - & - & - & - & - & - & - & - & - & - & - & - \\
\hline + 12 V supply & - & - & - & - & - & - & - & - & - & - & - & - \\
\hline-12 V supply & - & - & - & - & - & - & - & - & - & - & - & - \\
\hline $\begin{array}{l}7007 \\
\text { Silence }\end{array}$ & 1 & 1 & 1 & 0 & 0 & 0 & 0 & 0 & 0 & 1 & 1 & 1 \\
\hline
\end{tabular}

Figure 10. The 11 groups of four-digit octal words that report in detail on the health of the system.

Each capsule is programmed to recognize two acoustics commands consisting of a combination of four frequencies on and four frequencies off. Any other command combination is ignored. The number of frequencies allows us to work with a large number of capsules, and additional commands could be added for specific experiments. The new system also avoids the difficulties associated with the temporal approach and is extremely reliable.

\section{OBS COMPUTER AND OPERATIONAL SOFTWARE}

The microcomputer chip used in the Scripps' OBSs is an Intersil IM6100 CMOS device which we have chosen to clock at a relatively low speed of $2 \mathrm{MHz}$. This frequency was chosen as a reasonable compromise between current drain and computational speed. The IM6100 was one of the few CMOS microprocessors available at the time the OBSs were originally designed, and it had the advantage of a 12-bit word and compatibility with the Digital Equipment Corporation's PDP8/E minicomputer. This compatibility allowed the use of the OS/8 operating system with attendant editors, assemblers, and FORTRAN and BASIC high-level languages. (PDP8/E and $O S / 8$ are trademarks of the Digital Equipment Corporation.) In addition, a development system was available from Pacific Cyber Metrix (Pacific Cyber Metrix, 3120 Crow Canyon Road, San Ramon, CA 94583) which included interfaces for floppy and hard discs, line printers, and RS232 communications.

The oscillator used to clock the computer is a temperature-compensated crystal oscillator rather than an oven-controlled system, which would have required substantially more power. The drift rates observed for all the instruments are given in the OBS operational summary in Table 1. We do not attempt to set the frequency of the oscillators to match Universal Coordinated Time exactly, so each OBS has a net drift with respect to the correct time. The operational summary shows that this rate of drift from launch to launch is nearly constant and that the required time corrections are quite accurate. The computer real-time clock counts seconds with a double precision 24-bit word.

The system was originally configured with three 4000word blocks of CMOS memory. One of these blocks was reserved for program storage and operation and can be write-protected in 1000-word sections. Although the data are sampled at 128 samples/s, the computer actually writes 144 words/s to the tape in order to provide timing, gain, and other checks. The available memory, the
8000 words remaining outside the program area, was thus filled every $2 \times 4096 /(144 \times 4)=14.2$ s. Without additional memory, the system could record only for this period of time before turning the noisy tape recorder on. The Uher tape recorder could record data for approximately $6.5 \mathrm{hr}$. in a serial format on 1/4-in. magnetic tape. The total capacity of the system is about 159 megabits (Mbits), which contrasts with 368 Mbits on a 2400-ft, 9-track tape written at 1600 BPI (bits per inch).

The software that operates the seismographs is written in assembly language to ensure compact storage and efficiency. A number of control variables can be changed at checkout time, which allows considerable flexibility in experiment design and execution. Many of these variables must be written in double precision, and some of the calculations done in the determination of noise levels require triple precision (36 bits). A good initial example of a control loop in the OBS computer involves the collection of periodic noise records on the seafloor. This portion of the program, referred to as "Auto Noise Record," is controlled by three variables. The first variable is a double precision entity composed of the words ANRLSB and ANRMSB where LSB and MSB denote the least and most significant words of the pair. These two words determine the time of the first automatic noise recording with respect to the time the clock in the OBS is reset prior to launch. This pair of variables was set on each OBS during the teleseismic recording portion of the experiment to ensure the noise windows opened simultaneously to allow later processing for coherence across the array. The next variable (ANRTML, ANRTMM) specifies the intervals for repetition of the recording and is normally set to $4 \mathrm{hr}$. We did change this variable for the Ngendei experiment to ensure that tape usage for noise recording did not seriously affect the number of teleseisms we could record. The last variable controlling the automatic noise recording is the single word ANRREC, which is the duration in seconds of the noise recordings.

Prior to the Ngendei experiment, we added considerable CMOS memory to the system to allow recording of noise and teleseisms without interference from the rotation of the tape recorder. Additional 65,536-word memory boards can be added to the recorder up to a maximum of four boards. The single precision variable KPTR describes the number of boards installed; each board adds approximately $113 \mathrm{~s}$ of memory for all four channels and greatly extends the noiseless recording time available to the system. When the capsule is configured with the expanded memory area, the 8192-word memory 
boards usually in use are removed. The 12-bit word of the computer normally permits only 4096 words to be addressed in memory. An additional "memory extender" card is added to permit a larger address space; during operations with the 64,000-word boards this board is also removed. The large memory boards are not treated as random access memory (RAM), as was the case with the normal 8192-word CMOS memory, in that the software and hardware permit only serial writes and reads in a circular fashion within the augmented memory space. The controller board for the large-scale memory keeps pointers available to the current read and write positions, but arbitrary access is not facilitated. This practice eliminates the need for an enormously expanded address space, does not require additional computer power to operate the memory extender (which would otherwise be required), and reduces the power supply load. The full complement of 65,536-word boards actually draws less power than the normal 8192 words used as RAM! Because the system was new for this experiment, it was used only during the teleseismic portion of Ngendei and then only on four of the six available capsules. The added memory worked without encountering any problems and is now a routine part of capsule operations.

The setup of the seismographs was outlined in the earlier acoustics section and the function of the two variables (WAITLL, WAITMM) and (RUNTML, RUNTMM) was discussed. The setup portion of the program also controls the interval between subsequent leveling sequences through the double precision variable (TPTML, TPTMM). Normally this is set at $24 \mathrm{hr}$., but can be changed if desired. The system is periodically leveled to ensure that settling in the sediments does not introduce tilt.

The seismograph changes gain on the seafloor in response to changing noise levels to ensure that, on the one hand, seismic noise does not consume the entire dynamic range of the system and, on the other hand, the system is limited by ground noise at all times. The detection of noise levels on the seafloor requires that the system average detected levels over sufficiently long times that a stable estimate of noise is available for setting these gains. This process involves the calculation of both short term averages (STA) and long term averages (LTA); the LTA is actually calculated using the results of the STA. The STA is calculated by summing the absolute levels (128 of them for each channel) over the period of a second. The LTA is then updated by the most recent STA. The computer updates the gain of each channel individually every GANWAT where GANWAT is normally $512 \mathrm{~s}$. The gain is adjusted to ensure that the value of the LTA lies within a pair of bounds specified by the investigator. The two double precision variables are (LOBNDL, LOBNDM) and (UPBNDL, UPBNDM) and are normally set to $8 \times 2^{7}$ and $20 \times 2^{7}$ where the $2^{7}$ multiplier is a constant used in the calculation and the digital levels are 8 and 20 counts. During a noise study it might be desirable to raise these levels in order to keep the gain high enough to record all frequencies of interest at amplitudes in excess of the digitizing noise level. The STA and LTA are also calculated using the true rather than the absolute values of the levels for each channel. These av- erages should be zero, but may vary because of offsets in the analog amplifiers. This average is subtracted from the data prior to recording and trigger calculations.

The recording capacity of the seismograph is obviously limited by the tape storage so that triggering on earthquakes is necessary. The trigger system on the Scripps OBSs is relatively simple, although it is adaptive to ensure that a given experiment will come as close as possible to filling the tape. If the STA mentioned above exceeds $R \times$ LTA for two consecutive seconds on the vertical channel, a trigger occurs, the auxiliary memory is energized and the recorder is turned on some time later. The variable $R$ is adjusted by the computer and can vary from 2 to 15 . Two single precision variables control the setting of $R$ and are called TRGMIN and TRGMAX. If the number of triggers exceeds TRGMAX in a specified time period, $R$ is increased by 1 and if the triggers are less than TRGMIN, $R$ is decreased by 1 . The time interval involved is controlled by the double precision variable (TRGTML, TRGTMM) and is normally set to $24 \mathrm{hr}$. The investigator must choose these variables to ensure that the required number of triggers will approximately fill the available recording capacity for the length of the experiment. Experience at the Ngendei site showed that the noise was sufficiently stationary that the trigger ratio should be 3 at all times. The variable TRGMIN was set at 2-4 and TRGMAX was set to a very large number to ensure that the trigger ratio was actually driven to 3 and remained there. Two variables had to be changed to ensure the trigger ratio did not drop below 3 . These single precision variables, RATIO1 and RATIO2, are normally set to 2 and -3 . When an adjustment is to be made to the trigger ratio, the current value minus 1 is compared to $-(-3)$. If this is greater than $-(-3)$, the trigger ratio is decremented, but if it is less than or equal to $-(-3)$ the trigger ratio is set to 2 . The values of RATIO1 and RATIO2 were changed to 3 and -4 for the teleseismic portion of the Ngendei experiment. A final variable, TRIGRAT, controls the initial trigger level of the system. This is normally set to 4 , but some OBSs were set up with TRIGRAT $=3$ in order to minimize the time period the instruments required for reaching the desired trigger level. When experience with a particular site is not available prior to an extended launch, the "intelligence" built into the trigger could be very helpful.

The conduct of an explosion seismology experiment with a digital OBS requires that the capsule recognize a shooting schedule to ensure that seismograms will be recorded at the correct times. The computer in the OBS recognizes a refraction schedule composed of a series of four variables. The first variable is a double precision number and contains the time, following capsule time reset during launch preparation, at which a recording series is to be started. The second word is a single precision variable that contains the duration of the recording interval in seconds. The third word contains the time interval between shots, and the fourth indicates the number of shots.

The final set of variables contains times that control the action of the tape recorder with respect to the data that is in memory. Recall that KPTR $\times 113$ is the num- 
ber of seconds in the auxiliary memory. The single precision variable RECDLY is the number of seconds from a trigger decision until the recorder is turned on: normally this is set to $100 \mathrm{~s}$ when one memory board is in place. The system must also know how long to record after the STA is no longer able to assure a trigger condition. This must inevitably occur for a signal of any size since the LTA, with a time constant of $1024 \mathrm{~s}$, will eventually grow and approximate the size of the STA. This recording time is set in the single precision variable MTRMS and is calculated from the relationship MTRMX $=$ buffer size + post trigger recording interval +1 . Finally a single precision variable TRGDLY locks out the trigger algorithm for TRGDLY - $5 \mathrm{~s}$ after the tape recorder turns off. Normally TRGDLY is set to $12 \mathrm{~s}$ to ensure the tape recorder turnoff transient does not cause another false trigger. This is very important, given that MTRMX is usually quite large to ensure that most of the teleseismic wavetrain is recorded.

Table 3 lists these variables, their functions, and their default values, while Table 4 lists the variables that differed from their default values during the various Ngendei OBS deployments.

\section{OBS POWER SUPPLY}

The Scripps OBSs are powered from a combination of alkaline and $\mathrm{Li} / \mathrm{SO}_{4}$ cells. The bulk of the power is obtained from the high capacity lithium cells to minimize space and weight requirements, although this choice of chemistry demands care in handling the batteries. The power packs have been especially designed to minimize the chances of inappropriate handling.

The 6-V power supply consists of a pair of $3-\mathrm{V}, 30$ Amp-hr. cells in series. The $12-\mathrm{V}$ power supply is obtained from another pair of these cells driving an inverter. The power for the leveling mechanism and the tape recorder is taken from three $10-\mathrm{Amp}-\mathrm{hr}$. cells in series to provide the $7.5 \mathrm{~V}$ needed by the Uher tape recorder.

The alkaline cells power the acoustics, the timed releases, and the board used to detect the acoustic command for release. Twenty-four AA cells and $4 \mathrm{C}$ cells power the acoustics, while 4 AA cells are used for each of the release boards. The power for firing the explosive

Table 3. The important variables in the OBS software.

\begin{tabular}{|c|c|c|}
\hline Variable & Function & Default \\
\hline ANREC & Length of auto noise record & $60 \mathrm{~s}$ \\
\hline ANRLSB, ANRMSB & Time from clock reset to first auto noise record & Os \\
\hline ANRTML, ANRTMM & Time interval between auto noise records & $12 \mathrm{hr}$ \\
\hline GANWAT & Length of time between gain adjustments & $512 \mathrm{~s}$ \\
\hline KPTR & Number of auxiliary memory boards & 1 \\
\hline L & Number of consecutive seconds for trigger & 2 \\
\hline LOBNDL, LOBNDM & Minimum number of triggers in specified time period & $8 \times 2$ \\
\hline MTRMAX & Used to compute \# seconds of record after trigger end & $154 \mathrm{~s}$ \\
\hline RECDLKY & " of seconds after trigger for recorder start & $100 \mathrm{~s}$ \\
\hline RATIO1 & Used to set the minimum trigger ratio of the system & 2 \\
\hline RATIO2 & & -3 \\
\hline RUNTML, RUNTMM & Number of seconds in setup run & $4096 \mathrm{~s}$ \\
\hline TPTML, TPTMM & Time interval between seismic levelings & $24 \mathrm{hr}$ \\
\hline TRIGRAT & Beginning trigger ratio & 4 \\
\hline TRGDLY & $\begin{array}{l}\text { Calculates \# seconds after recorder turnoff for trigger } \\
\text { restart }\end{array}$ & $12 \mathrm{~s}$ \\
\hline TRGMIN & Minimum \# triggers in specified period & 1 \\
\hline TRGMAX & Maximum $A$ triggers in specified period & 4 \\
\hline TRGTML, TRGTMM & Time interval over which to check trigger \# & $24 \mathrm{hr}$ \\
\hline UPBNDL, UPBNDM & Maximum \# of triggers in a specified time period & $20 \times 2$ \\
\hline WAITLL, WAITMM & Time interval from first diagnostics to leveling & $3 \mathrm{hr}$. \\
\hline
\end{tabular}

Table 4. Assignment of variables for the OBS launches during the Ngendei experiment.

\begin{tabular}{|c|c|c|c|}
\hline OBS & Launch date & Variable & Value \\
\hline \multicolumn{4}{|c|}{ OBS refraction } \\
\hline KAREN & $28 \mathrm{Jan} 83$ & No changes & \\
\hline JUAN & 29 Jan 83 & $\begin{array}{l}\text { LOBNDL, LOBNDM } \\
\text { UPBNDL, UPBNDM }\end{array}$ & $\begin{array}{l}16 \times 2^{7} \\
40 \times 2^{7}\end{array}$ \\
\hline SUZY & 29 Jan 83 & No changes & \\
\hline LYNN & 30 Jan 83 & $\begin{array}{l}\text { LOBNDL, LOBNDM } \\
\text { UPBNDL, UPBNDM }\end{array}$ & $\begin{array}{l}16 \times 2^{7} \\
40 \times 2^{7}\end{array}$ \\
\hline \multicolumn{4}{|c|}{ Initial teleseismic recording } \\
\hline PHRED & 23 Jan 83 & $\begin{array}{l}\text { ANRLSB, ANRMSB } \\
\text { ANRTML, ANRTMM } \\
\text { TRGMIN } \\
\text { TRGMAX }\end{array}$ & $\begin{array}{l}7 \mathrm{hr}, 50 \mathrm{~min} . \\
3 \mathrm{hr} . \\
6 \\
18\end{array}$ \\
\hline JANICE & $24 \operatorname{Jan} 83$ & $\begin{array}{l}\text { ANRLSB, ANRMSB } \\
\text { ANRTML, ANRTMM } \\
\text { TRGMIN } \\
\text { TRGMAX }\end{array}$ & $\begin{array}{l}7 \mathrm{hr}, 40 \mathrm{~min} . \\
3 \mathrm{hr} . \\
4 \\
12\end{array}$ \\
\hline \multicolumn{4}{|c|}{ Teleseismic recording period } \\
\hline JANICE & 5 Feb 83 & $\begin{array}{l}\text { ANRLSB, ANRMSB } \\
\text { ANRTML, ANRTMM } \\
\text { RATIO1 } \\
\text { RATIO2 } \\
\text { TRGMIN } \\
\text { TRGMAX }\end{array}$ & $\begin{array}{l}85 \mathrm{hr} ., 30 \mathrm{~min} \\
24 \mathrm{hr} . \\
3 \\
-4 \\
2 \\
6\end{array}$ \\
\hline PHRED & 9 Feb 83 & $\begin{array}{l}\text { ANRLSB, ANRMSB } \\
\text { ANRTML, ANRTMM } \\
\text { RATIO1 } \\
\text { RATIO2 } \\
\text { TRGMIN } \\
\text { TRGMAX } \\
\text { TRIGRAT }\end{array}$ & $\begin{array}{l}30 \mathrm{hr} ., 20 \mathrm{~min} \\
24 \mathrm{hr} . \\
3 \\
-4 \\
4 \\
16 \\
3\end{array}$ \\
\hline SUZY & $10 \mathrm{Feb} 83$ & $\begin{array}{l}\text { ANRLSB, ANRMSB } \\
\text { ANRTML, ANRTMM } \\
\text { RATIO1 } \\
\text { RATIO2 } \\
\text { TRGMIN } \\
\text { TRGMAX } \\
\text { RECDLY }\end{array}$ & $\begin{array}{l}29 \mathrm{hr} ., 30 \mathrm{~min} \\
24 \mathrm{hr} . \\
3 \\
-4 \\
4 \\
16 \\
90 \mathrm{~s}\end{array}$ \\
\hline JUAN & 11 Feb 83 & $\begin{array}{l}\text { ANRLSB, ANRMSB } \\
\text { ANRTML, ANRTMM } \\
\text { RATIO1 } \\
\text { RATIO2 } \\
\text { TRGMIN } \\
\text { TRGMAX }\end{array}$ & $\begin{array}{l}15 \mathrm{hr} ., 50 \mathrm{~min} \\
24 \mathrm{hr} . \\
3 \\
-4 \\
4 \\
16\end{array}$ \\
\hline KAREN & 11 Feb 83 & $\begin{array}{l}\text { ANRLSB, ANRMSB } \\
\text { ANRTML, ANRTMM } \\
\text { MTRMAX } \\
\text { RATIO1 } \\
\text { RATIO2 } \\
\text { TRGMIN }\end{array}$ & $\begin{array}{l}27 \mathrm{hr} ., 25 \mathrm{~min} \\
24 \mathrm{hr} . \\
240 \mathrm{x} \\
3 \\
-4 \\
2\end{array}$ \\
\hline LYNN & 12 Feb 83 & $\begin{array}{l}\text { ANRLSB, ANRMSB } \\
\text { MTRMAX } \\
\text { RATIO1 } \\
\text { RATIO2 } \\
\text { TRGMIN }\end{array}$ & $\begin{array}{l}3 \mathrm{hr} ., 29 \mathrm{~min} . \\
300 \mathrm{~s} \\
3 \\
-4 \\
2\end{array}$ \\
\hline
\end{tabular}

bolts is provided by three $9-\mathrm{V}$ alkaline batteries connected in series; each timed release board contains one of these power packs, while the acoustics release board uses two of the packages. The power for the release boards is entirely separate, and the electronics and required oscillators are isolated from the main computer to ensure a maximum amount of reliability through redundancy. None of these instruments have ever been lost at sea, largely because of the care given to this design.

The OBSs were left on the bottom for over 45 days during the teleseismic recording portion of the Ngendei experiment. The instruments draw less than $400 \mathrm{~mW}$ when 
not recording, and, given the conservatism of the manufacturer's specifications for battery capacity, the seismographs are capable of deployments at least as long as 60 days with the current battery complement.

\section{CONCLUSIONS}

The OBSs from the Scripps Institution of Oceanography performed exceptionally well during the course of the Ngendei seismic experiment. Several deployments lasted for more than 45 days and, in each case, the capsules returned high-quality data. Difficulties with the response of the horizontal channels were encountered in a number of instances (as described in other papers in this volume), and a satisfactory solution to this instrumentation problem has not been found. The use of software to control the operating characteristics of the seismographs was largely successful, although the flexibility of the system is still limited by the rather primitive nature of the processor being used for capsule operation. Many of the water waves recorded by the instruments were clipped in the digitization process. We have found such data to be extremely valuable in evaluating the structure of the shallow seafloor. Modifications to the system to permit "dynamic" gain ranging or, equivalently, a floating-point digitizing scheme would be very desirable.

\section{REFERENCES}

Creager, K. C., and Dorman, L. M., 1982. Location of instruments on the seafloor by joint adjustment of instruments and ship positions. J. Geophys. Res., 87:8379-8388.

Moore, R. D., Dorman, L., Huang, C. Y., and Berliner, D., 1981. An ocean bottom microprocessor based seismometer. Mar. Geophys. Res., 4:457-477.

Prothero, W. A., 1979. Earthquake signal processing and logging with a battery-powered microcomputer. Bull. Seism. Soc. Am., 70:22752290.

Riedesel, M., Orcutt, J. A., Macdonald, K. C., and McClain, J. S., 1982. Microearthquakes in the black smoker hydrothermal field, East Pacific Rise. J. Geophys. Res., 87:10613-10623.

Date of Initial Receipt: 12 April 1985

Date of Acceptance: 25 September 1985 